(c) American Dairy Science Association, 2004.

\title{
Heritability and Correlations for Body Condition Score and Dairy Form Within and Across Lactation and Age
}

\author{
C. D. Dechow, ${ }^{1}$ G. W. Rogers, ${ }^{1}$ L. Klei, ${ }^{2}$ and T. J. Lawlor ${ }^{2}$ \\ ${ }^{1}$ Dept. of Animal Science, University of Tennessee, \\ Knoxville 37996 \\ ${ }^{2}$ Holstein Association USA Inc., \\ Brattleboro, VT 05302
}

\begin{abstract}
The objectives of the current study were to investigate the relationship between body condition score (BCS) and dairy form and changes in genetic parameters for BCS and dairy form within and across lactations and age. Body condition score and dairy form were obtained from the Holstein Association USA, Inc. Records were edited to include those cows classified between 24 and 60 mo of age and between 0 and $335 \mathrm{~d}$ in milk (DIM). A minimum of 20 daughters per sire and 15 cows per herd-classification visit were required. The dataset consisted of 135,178 records from 119,215 cows. Repeatability, multiple trait, and random regression models were used to analyze the data. All models included fixed effects for herd-classification visit, age within lactations 1,2 , and 3 or higher, and 5th-order polynomials for DIM. Random effects included sire and permanent environment for all models. Random regression models included age at classification nested within sire or DIM and lactation number nested within sire. Genetic variance for both BCS and dairy form was lowest in early lactation and highest in midlactation. Genetic correlations within and across lactations were high. The genetic correlation between DIM 0 in lactation 1 and DIM 305 in lactation 3 was estimated to be 0.77 for BCS and 0.60 for dairy form. The genetic correlation estimate between 30 mo of age at classification and 50 mo of age at classification was 0.94 for both dairy form and BCS. The repeatability models appeared to generate accurate evaluations for BCS or dairy form at all ages and stages of lactation.
\end{abstract}

(Key words: body condition score, dairy form, random regression)

Abbreviation key: $\mathbf{B C S}=$ body condition score, $\mathbf{B C S}_{\mathbf{X}}=$ BCS on DIM X, $\mathbf{B C H} \mathbf{X - Y}=$ BCS on DIM X minus BCS on DIM Y, $\mathbf{B C H}_{\mathrm{DP}}=$ BCS on DIM 0 in lactation

Received January 23, 2003.

Accepted June 20, 2003.

Corresponding author: C. Dehow; e-mail: cdechow@tennessee.edu.
2 - DIM 305 in lactation $1, \mathbf{D F}_{\mathbf{X}}=$ dairy form on DIM $\mathrm{X}, \mathbf{D C H}_{\mathbf{X}-\mathbf{Y}}=$ dairy form on DIM X minus dairy form on DIM Y, HEV = heterogeneous residual variance, HOV = homogeneous residual variance, $\mathbf{L}=$ lactation number, $\mathbf{L G}=$ lactation group, $\mathbf{L G} \mathbf{1}=$ lactation group 1, LG2 = lactation group 2, LG3 = lactation group 3, $\mathbf{L P}=$ Legendre polynomial, $\mathbf{L P 0}=$ intercept, $\mathbf{L P 1}=$ linear Legendre polynomial, LP2 = quadratic Legendre polynomial, MDRR = multidimensional random regression, $\mathbf{M T}=$ multiple trait, $\mathbf{P E}=$ permanent environment, $\mathbf{R P T}=$ repeatability, $\mathbf{R R A}=$ random regression on age.

\section{INTRODUCTION}

Body condition score and dairy form are genetically similar traits that are related to production, cow health, and reproductive performance. The genetic correlation between BCS and dairy form score in the United States has been estimated to be -0.72 (Dechow et al., 2003).

Body condition score is favorably correlated genetically with days to first heat, days to first service, conception rates, and calving intervals (Dechow et al., 2001; Pryce et al., 2001; Veerkamp et al., 2001). Higher levels of BCS are also genetically correlated with lower milk yield in the above studies, but the genetic relationship between BCS and reproductive performance exists after adjustment for yield. Higher BCS loss during early lactation is also related to higher production and poorer reproductive performance (Pryce et al., 2001; Dechow et al., 2002).

Dairy form has been genetically correlated with increased disease incidence after adjustment for milk yield (Rogers et al., 1999; Hansen et al., 2002). Despite the antagonistic relationship between dairy form and measures of cow health, selection has been practiced for higher dairy form in the United States because of a favorable relationship with production. The genetic correlation between dairy form and milk yield was reported to be 0.52 (Short and Lawlor, 1992).

Random regression models have been used to analyze BCS in first lactation in Europe (Jones et al., 1999; 
Veerkamp et al., 2001). Random regression models have also been used to analyze changes in genetic parameters for selected linear type traits and final score with age and to investigate changes in genetic parameters over time in the United States (Uribe et al., 2000; Tsuruta et al., 2002a, 2002b).

Random regression models have not been used to analyze changes in BCS or dairy form within lactation in the United States. Moreover, changes in BCS or dairy form with age or lactation number have not been investigated. Multidimensional random regression models allow investigation of changes both within lactation and across lactation number or age simultaneously (Jensen, 2001).

The objectives of the current study were to: 1 ) investigate changes in genetic parameters for BCS and dairy form within and across lactations using multidimensional random regression models, 2) investigate changes in genetic parameters with age for BCS and dairy form using random regression models, and 3) further investigate the relationship between BCS and dairy form.

\section{MATERIALS AND METHODS}

\section{Data}

Body condition and dairy form scores were obtained from the Holstein Association USA, Inc. (Brattleboro, VT). The initial dataset included 728,597 records on 613,338 cows that were recorded from October of 1997 through June of 2000. Body condition score is recorded on a scale of 1 (thin) to 50 (fat). Body condition score was a new trait for classifiers and BCS were not distributed normally for many classifiers. Therefore, records from classifiers that assigned BCS abnormally were eliminated with the same procedures used in Dechow et al. (2003).

Cows that were classified before 24 mo of age or later than 60 mo of age were eliminated to be consistent with the data editing procedures used for the national genetic evaluations. Classification scores do not decline for cows greater than 60 mo of age in the United States. Cows that were more than 335 DIM were eliminated. Additional data edits included a requirement of 20 daughters per sire and 15 cows for each herd-classification visit. Edits for a minimum number of daughters per sire and cows per herd-classification visit were necessary to make parameter estimation computationally feasible. However, there is no minimum number of daughters required for the national genetic evaluations, and all cows from contemporary groups of two or more are retained.

The final dataset included 135,178 records from 119,215 cows. There were 80,967 first-lactation records,
40,468 second-lactation records, and 13,743 records from third to fifth lactations. Within a given lactation, 4768 cows had two records and 26 cows had 3 records. Across lactations, 10,301 cows had records in two lactations, whereas 421 cows had records in 3 lactations.

The cows were sired by 827 bulls and were evaluated in 4726 herd-classification visits. Three generations of sires and dams were traced for each sire resulting in a pedigree file that included 1654 animals.

\section{Analyses}

Sire models for BCS or dairy form were performed with ASREML (Gilmour et al., 2002). Several models described below were used to analyze the data. Likelihood ratio tests were used to test the significance of random effects in random regression models (Gilmour et al., 2002).

Repeatability models (RPT). Body condition and dairy form scores on the same cow at different DIM and in different lactations were considered repeated observations of the same trait. The statistical model is described below:

$$
\begin{gathered}
\mathrm{y}_{\mathrm{ijk} \mathrm{k} m}=\mathrm{hd}_{-} \mathrm{cl}_{\mathrm{i}}+\mathrm{b}_{1} * \operatorname{age}\left(\mathrm{LG}_{\mathrm{j}}\right) \\
+\sum_{\mathrm{k}=2}^{6} \mathrm{~b}_{\mathrm{kj}} * \mathrm{DIM}^{\mathrm{k}-1}\left(\mathrm{LG}_{\mathrm{j}}\right)+\operatorname{Sire}_{1}+\mathrm{PE}_{\mathrm{m}}+\varepsilon_{\mathrm{ijk} \mathrm{m}}
\end{gathered}
$$

where $\mathrm{y}_{\mathrm{ijk} k \mathrm{~m}}=\mathrm{BCS}$ or dairy form. Fixed effects were: hd_cl $\mathrm{i}_{\mathrm{i}}=$ herd-classification visit $\mathrm{i}, \mathrm{b}_{1}=$ a regression coefficient on age at calving nested within lactation group $\mathrm{j}, \mathrm{b}_{\mathrm{kj}}=$ regression coefficients on DIM of order 1 to 5 nested within lactation group $\mathrm{j}$, and $\mathrm{LG}_{\mathrm{j}}$ were lactation groups consisting of first-lactation cows (LG1), secondlactation cows (LG2) and third- through fifth-lactation cows (LG3). Random effects included: Sire $_{1}=$ effect of sire $1, \mathrm{PE}_{\mathrm{m}}=$ permanent environmental effect for cow $\mathrm{m}$, and $\varepsilon_{\mathrm{ijklm}}=$ random error .

Random regression on age at classification models $(\boldsymbol{R R} \boldsymbol{R})$. Changes in random genetic and permanent environment effects were considered a function of age at classification with the model described below:

$$
\begin{gathered}
\mathrm{y}_{\mathrm{ijklmnp}}=\mathrm{hd}_{-} \mathrm{cl}_{\mathrm{i}}+\mathrm{b}_{\mathrm{1}} * \operatorname{age}\left(\mathrm{LG}_{\mathrm{j}}\right)+\sum_{\mathrm{k}=2}^{6} \mathrm{~b}_{\mathrm{kj}} * \mathrm{DIM}^{\mathrm{k}-1}\left(\mathrm{LG}_{\mathrm{j}}\right)+ \\
\sum_{\mathrm{n}=0}^{1} \operatorname{Sire}_{\mathrm{l}} * \mathrm{~b}_{\mathrm{ln}} * \operatorname{age}_{\mathrm{p}}{ }^{\mathrm{n}}+\sum_{\mathrm{n}=0}^{1} \mathrm{PE}_{\mathrm{m}} * \mathrm{~b}_{\mathrm{mn}} * \operatorname{age}_{\mathrm{p}}{ }^{\mathrm{n}}+\varepsilon_{\mathrm{ijklmnp}},
\end{gathered}
$$

where $\mathrm{y}_{\mathrm{ijklmnp}}=\mathrm{BCS}$ or dairy form, and the fixed effects are the same as described for model 1, except age at calving is replaced with age at classification, $b_{\mathrm{ln}}=$ random regression coefficients of order 0 to 1 on age at 
classification $p$ for sire $1, b_{m n}=$ random regression coefficients of order 0 to 1 on age at classification $p$ for the permanent environmental effects of cow $\mathrm{m}$, and $\varepsilon_{\mathrm{ijklmnp}}=$ random error.

Convergence was not obtained for BCS or dairy form models that included random regression coefficients for age $_{\mathrm{p}}{ }^{2}$. Random error variance was allowed to vary for the following age at classification groups: 24 to 30,31 to 35,36 to 40,41 to 45,46 to 50,51 to 55 , and 56 to $60 \mathrm{mo}$.

This model allows generation of sire transmitting abilities for any age at classification. Additionally, sire transmitting abilities for change in daughter BCS or dairy form as they mature can be calculated.

Multidimensional random regression on DIM and lactation number models (MDRR). Changes in random genetic and permanent environment effects were considered a function of DIM and lactation number and are described by the model below:

$$
\begin{gathered}
\mathrm{y}_{\mathrm{ijkmnpq}}=\text { fixed }_{\text {effects }}+\sum_{\mathrm{p}=0}^{2} \text { Sire }_{\mathrm{jp}} \phi_{\mathrm{pk}}+\text { Sire }_{\mathrm{jm}} \mathrm{L}_{\mathrm{m}} \\
+ \text { Sire }_{\mathrm{j} 1 \mathrm{~m}} \phi_{1} \mathrm{~L}_{\mathrm{m}}+\sum_{\mathrm{q}=0}^{\mathrm{x}} \mathrm{PE}_{\mathrm{nq}} \phi_{\mathrm{qk}} \\
+\mathrm{PE}_{\mathrm{nm}} \mathrm{L}_{\mathrm{m}}+\varepsilon_{\mathrm{ijkmnpq}}
\end{gathered}
$$

where $\mathrm{y}_{\mathrm{ijkmnpq}}=\mathrm{BCS}$ or dairy form, fixed effects $\mathrm{s}_{\mathrm{i}}$ are the ith fixed effects and are identical to those described for model 1, Sire $_{j p}=$ random regression coefficient for sire $\mathrm{j}$ on a Legendre polynomial (LP) for DIM of order $\mathrm{p}, \phi_{\mathrm{pk}}=\mathrm{LP}$ of order $\mathrm{p}(\mathbf{L P 0}=$ intercept, $\mathbf{L P 1}=$ linear and LP2 = quadratic) for DIM $\mathrm{k}$, Sire $_{\mathrm{jm}}=$ random regression coefficient for sire $\mathrm{j}$ on lactation number $\mathrm{m}\left(\mathrm{L}_{\mathrm{m}}\right)$, Sir$e_{j 1 \mathrm{~m}}=$ random regression coefficient for sire $\mathrm{j}$ on $\mathrm{LP} 1 \times$ $\mathrm{L}_{\mathrm{m}}, \mathrm{PE}_{\mathrm{nq}}=$ random regression coefficient for permanent environmental effect of cow $\mathrm{n}$ on LP for DIM of order $\mathrm{q}, \phi_{\mathrm{qk}}=\mathrm{LP}$ of order $\mathrm{q}$ for DIM $\mathrm{k}, \mathrm{x}=1$ for BCS and 0 for dairy form, and $\varepsilon_{\mathrm{ijkmnpq}}=$ random error.

Legendre polynomials are orthogonal and can be used with random regression models to model smooth curves and growth trajectories (Kirkpatrick et al., 1990). Legendre polynomials are standardized to range from -1 (d 0) to 1 (d 335). An LP0 is a constant and for these analyses was set to 1 . Cubic LP for sire effects would not converge for BCS and did not improve the log-likelihood $(P=0.52)$ for dairy form.

Initial analyses attempted to fit sire and PE effects to identical order of LP. However, analyses of BCS including $\mathrm{PE} * \mathrm{LP} 2$ would not converge so only $\mathrm{PE} * \mathrm{LP} 1$ was fit. For analyses of dairy form, models including $\mathrm{PE} * \mathrm{LP} 1$ or $\mathrm{PE} * \mathrm{LP} 2$ would not converge.

A lack of cows with multiple records within lactation may have limited successful modeling of higher order
LP for PE. Only 4768 cows had 2 observations within a single lactation, and very few (26) cows had 3 observations within a single lactation.

Including Sire ${ }_{j 1 \mathrm{~m}} \phi_{1} \mathrm{~L}_{\mathrm{m}}$ improved the log likelihood significantly for dairy form $(P<0.001)$ and was included in the analysis of dairy form, but $\operatorname{Sire}_{j 1 \mathrm{~m}} \phi_{1} \mathrm{~L}_{\mathrm{m}}$ was not included in analysis of BCS $(P=0.75)$.

Two types of residual error structures were compared. Residual variance was assumed to remain constant across DIM and lactation for the first analyses. This first model assumed homogeneous residual variance (HOV). Residual variance was allowed to vary by month within LG for the second set of analyses. Consecutive months with similar residual variance were then grouped, resulting in the following 5 residual variance groups for each LG: mo 1, 2, 3 through 8, 9, and 10, and 11. In LG3, only 266 records were available for mo 11 , so mo 11 was grouped with mo 9 and 10 . This second model assumed heterogeneous residual variance (HEV).

The above models will allow the generation of sire transmitting abilities for any DIM between 0 and 335 in any lactation 1 through 3 (there were only 163 observations in lactations 4 and 5). Moreover, sire-transmitting abilities can be generated for change in BCS or dairy form between any two DIM in any lactation. Sire transmitting abilities for daughter change in BCS or dairy form as lactations progress could be generated.

Random regression model assumptions. Models 2 and 3 can be written in matrix notation as

$$
\mathbf{y}=\mathbf{X} \boldsymbol{\beta}+\mathbf{Z}_{1} \mathbf{a}+\mathbf{Z}_{2} \mathbf{p}+\mathbf{e}
$$

where $\mathbf{y}=$ a vector of BCS or dairy form, $\mathbf{X}$ is an incidence matrix for fixed effects, $\boldsymbol{\beta}$ is a vector of fixed effects, $\mathbf{Z}_{\mathbf{1}}$ is an incidence matrix for sire effects, $\mathbf{a}$ is a vector of random regression coefficients for sire effects, $\mathbf{Z}_{2}$ is an incidence matrix for permanent environmental effects, $\mathbf{p}$ is a vector of random regression coefficients for permanent environmental effects, $\mathbf{e}$ is a vector of residual effects. It was assumed that

$$
\left(\begin{array}{l}
\mathbf{a} \\
\mathbf{p} \\
\mathbf{e}
\end{array}\right) \sim \mathbf{N}(\mathbf{0}, \mathbf{V})
$$

and

$$
\mathbf{V}=\left(\begin{array}{ccc}
\mathbf{G} \otimes \mathbf{A} & \mathbf{0} & \mathbf{0} \\
\mathbf{0} & \mathbf{P} \otimes \mathbf{I}_{\mathbf{1}} & \mathbf{0} \\
\mathbf{0} & \mathbf{0} & \mathbf{R}
\end{array}\right)
$$


where $\mathbf{G}$ and $\mathbf{P}$ are the covariance matrices of random regression coefficients for sire and permanent environmental effects, respectively, and are assumed to be the same for all sires, $\mathbf{A}$ is the additive genetic relationship among sires, $\otimes$ is the direct product, $\mathbf{I}$ is an identity matrix with order equal to the number of cows, and $\mathbf{R}$ is a diagonal matrix of residual variances for models that assume $\mathrm{HEV}$, or residual variance for models that assume HOV.

For analysis of dairy form using model 3,

$$
\mathbf{G}=\mathbf{V}\left(\mathrm{a}_{\phi 0}, \mathrm{a}_{\phi 1}, \mathrm{a}_{\phi 2}, \mathrm{a}_{\mathrm{L}}, \mathrm{a}_{\mathrm{L} * \phi 1}\right)^{\prime} .
$$

Multiple-trait models (MT). Body condition score and dairy form were analyzed with two types of MT models. First, MT models with either BCS or dairy form in LG1, LG2, and LG3 treated as different traits were compared. A three-trait model was used for analysis of BCS. However, a three-trait model would not converge with dairy form because of genetic correlation estimates near the boundary of the parameter space. Therefore, 3 bivariate analyses were performed for dairy form to generate correlations among LG1, LG2, and LG3.

A second set of MT models were used to estimate correlations between BCS and dairy form at different lactation stages. The traits analyzed were BCS or dairy form in the following five lactation periods: mo 1 through 2, 3 through 4, 5 through 6,7 through 8 , and 9 through 11.

The statistical model is as follows:

$$
\begin{gathered}
\mathbf{y}=\mathbf{b}_{\mathbf{1}} * \text { age }+ \text { hd_cl }+\sum_{\mathrm{m}=2}^{6} \mathbf{b}_{\mathbf{x}} \\
* \mathrm{DIM}^{\mathrm{m}-1}+\text { Sire }+\mathbf{P E}+\varepsilon,
\end{gathered}
$$

where $\mathbf{y}=$ a vector of length 3 for BCS with LG1, LG2, and LG3 treated as separate traits, a vector of length 2 with dairy form from $2 \mathrm{LG}$, or a vector of length 2 with BCS and dairy form from the same lactation period, $\mathbf{b}_{1}=\mathbf{a}$ vector regression coefficients on age at calving, hd_cl = vector of fixed effects for herd-classification visit, $\mathbf{b}_{\mathbf{x}}=$ a vector of regression coefficients on DIM polynomials of order 1 through 5 , Sire $=$ a vector of random effects for sire, $\mathbf{P E}=$ a vector of random permanent environmental effects for cow, and $\varepsilon=$ random error.

Heritabilities, correlations, and PTA generated with the MT models were used to help assess the accuracy and fit of RPT and random regression models for a given lactation. The MT models for lactation period will also help assess the relationship between BCS and dairy form at different stages of lactation.

\section{Variance Derivation}

The matrix of random regression coefficients for sire with MDRR (model 3) is as follows for analysis of dairy form:

$$
\mathrm{C}_{\mathrm{S}}=\left[\begin{array}{lllll}
\sigma_{\phi 0}^{2} & & & & \\
\sigma_{\phi 0, \phi 1} & \sigma_{\phi 1}^{2} & & & \\
\sigma_{\phi 0, \phi 2} & \sigma_{\phi 1, \phi 2} & \sigma_{\phi 2}^{2} & & \\
\sigma_{\phi 0, \mathrm{~L}} & \sigma_{\phi 1, \mathrm{~L}} & \sigma_{\phi 2, \mathrm{~L}} & \sigma_{\mathrm{L}}^{2} & \\
\sigma_{\phi 0, \phi 1 * \mathrm{~L}} & \sigma_{\phi 1, \phi 1 * \mathrm{~L}} & \sigma_{\phi 2, \phi 1 * \mathrm{~L}} & \sigma_{\mathrm{L}, \phi 1 * \mathrm{~L}} & \sigma_{\mathrm{L} * \phi 1}^{2}
\end{array}\right]
$$

The last row and column would not be included in $\mathrm{C}_{\mathrm{S}}$ for BCS. The coefficient matrix for $\mathrm{PE} *$ effects $\left(\mathrm{C}_{\mathrm{PE}} *\right)$ will have the same general form as the coefficient matrix for sire effects. Because a sire model was used for this study, $3 / 4$ of the genetic variance is associated with the $\mathrm{PE}$ variance estimate. Therefore, $\mathrm{PE}^{*}$ variance will refer to $\mathrm{PE}$ variance $+3 / 4$ of the genetic variance, and $\mathrm{PE}$ variance to actual $\mathrm{PE}$ variance. The $\mathrm{C}_{\mathrm{PE}^{*}}$ for $\mathrm{BCS}$ will not contain the third and last rows and columns, whereas $\mathrm{C}_{\mathrm{PE}^{*}}$ for dairy form would only contain the first and fourth rows and columns.

The design matrix for random sire effects for DIM w and $\mathrm{x}$ in lactations $\mathrm{y}$ and $\mathrm{z}$ for dairy form is:

$$
\mathrm{D}_{\mathrm{wx}, \mathrm{yz}}=\left[\begin{array}{ccccc}
1 & \phi_{1 \mathrm{w}} & \phi_{2 \mathrm{w}} & \mathrm{L}_{\mathrm{y}} & \phi_{1 \mathrm{w}} * \mathrm{~L}_{\mathrm{y}} \\
1 & \phi_{1 \mathrm{x}} & \phi_{2 \mathrm{x}} & \mathrm{L}_{\mathrm{z}} & \phi_{1 \mathrm{x}} * \mathrm{~L}_{\mathrm{z}}
\end{array}\right]
$$

The design matrix for BCS sire effects will not have the last column, whereas the design matrix for BCS PE effects will not have the third and last columns and the design matrix for dairy form PE effects will have only the first and fourth columns.

The sire variance/covariance matrix for DIM w and $\mathrm{x}$ in lactations $\mathrm{y}$ and $\mathrm{z}$ would then be: $\sigma_{\text {Sire }, \mathrm{wx}, \mathrm{yz}}^{2}=\mathrm{D}_{\mathrm{wx}, \mathrm{yz}}$ $\mathrm{C}_{\mathrm{S}} \mathrm{D}_{\mathrm{wx}, \mathrm{yz}}{ }^{\prime}$. Likewise, the $\mathrm{PE}^{*}$ variance/covariance matrix for DIM $\mathrm{w}$ and $\mathrm{x}$ in lactations $\mathrm{y}$ and $\mathrm{z}$ would be: $\sigma_{\mathrm{PE}, \mathrm{wx}, \mathrm{yz}}^{2}=\mathrm{D}_{\mathrm{wx}, \mathrm{yz}} \mathrm{C}_{\mathrm{PE}^{*}} \mathrm{D}_{\mathrm{wx}, \mathrm{yz}}{ }^{\prime}$.

To determine sire or PE variance for change in BCS or dairy form from day $\mathrm{x}$ to $\mathrm{y}$, the design matrix coefficients for day y are subtracted from the design matrix coefficients for $\mathrm{x}$. For example, to determine the sire variance/covariance among BCS on DIM 0 and 70 , and change in BCS from DIM 0 to 70 in first lactation, the following design matrix would be used.

$$
\mathrm{D}_{0,70}=\left[\begin{array}{llll}
1 & -1.225 & 1.580 & 1 \\
1 & -0.713 & 0.013 & 1 \\
0 & -0.512 & 1.567 & 0
\end{array}\right]
$$


The variance/covariance matrix among BCS on $\mathrm{d} 0$ and 70, and change in BCS from d 0 to 70 in first lactation is then derived as: $\mathrm{D}_{0,70} \mathrm{C}_{\mathrm{S}} \mathrm{D}_{0,70}$ '.

Genetic variance on day $\mathrm{x}$ in lactation $\mathrm{y}\left(\sigma_{\mathrm{A}, \mathrm{xy}}^{2}\right)$ was calculated as $4 * \sigma_{\text {Sire,xy. The }}^{2} \mathrm{PE}$ variance on day $\mathrm{x}$ in lactation y can be calculated as $\sigma_{\mathrm{PE}, \mathrm{xy}}^{2}=\sigma_{\mathrm{PE}^{*}, \mathrm{xy}}^{2}-3 *$ $\sigma_{\text {Sire,xy }}^{2}$

The phenotypic variance was calculated as $\sigma_{\mathrm{P}, \mathrm{xy}}^{2}=$ $\sigma_{\mathrm{A}, \mathrm{xy}}^{2}+\sigma_{\mathrm{PE}, \mathrm{xy}}^{2}+\sigma_{\varepsilon, \mathrm{z}}^{2}$, where day $\mathrm{x}$ in lactation y was included in residual group $\mathrm{z}$. Heritability $\left(\mathrm{h}_{\mathrm{xy}}^{2}\right)$ was $\left(\sigma_{\mathrm{A}, \mathrm{xy}}^{2} / \sigma_{\mathrm{P}, \mathrm{xy}}^{2}\right.$. The phenotypic covariance between day $\mathrm{w}$ and $\mathrm{x}$ in lactation $\mathrm{y}$ and $\mathrm{z}$ was calculated as $\sigma_{\mathrm{P}, \mathrm{wx}, \mathrm{yz}}=$ $\sigma_{\mathrm{A}, \mathrm{wx}, \mathrm{yz}}+\sigma_{\mathrm{PE}, \mathrm{wx}, \mathrm{yz}}$. Phenotypic variance for the change in BCS or dairy form from day $\mathrm{w}$ to $\mathrm{x}$ in lactations $\mathrm{y}$ and $\mathrm{z}$ could then be calculated as: $\sigma_{\mathrm{P}, \mathrm{wx}, \mathrm{yz}}^{2}=\sigma_{\mathrm{P}, \mathrm{wy}}^{2}+$ $\sigma_{\mathrm{P}, \mathrm{xz}}^{2}-2 * \sigma_{\mathrm{P}, \mathrm{wx}, \mathrm{yz}}$.

Generating variances with model 2 (RRA) is similar to model 3 (MDRR). Days in milk is not included in the model so the size of the coefficient and design matrices are smaller. Lactation number is replaced with age at classification and the procedures used to calculate variances and variance ratios for MDRR are used.

\section{Predicted Transmitting Abilities}

Sire predicted transmitting abilities for BCS and dairy form from model 4 (MT) and model 1 (RPT) were obtained from ASREML output. Average PTA for lactations 1, 2, and 3 were generated from model 3 (MDRR). Additionally, PTA for 30 and 50 mo of age at classification were generated from model 2 (RRA).

Correlations were generated among all of the PTA. Low correlation estimates between PTA from the RPT models and PTA from random regression models could indicate ill-fitted random regression models or that RPT models are inadequate for certain DIM or ages. Correlations among specific lactation PTA from MT and MDRR models that were higher than correlations between MT and RPT PTA would indicate that MDRR models are more accurate for specific lactations than RPT models. These correlations can also help determine at what age or lactation number national genetic evaluations are most accurate.

\section{RESULTS AND DISCUSSION}

\section{RPT Models}

Generalized least square solutions from RPT models for BCS and dairy form across LG1, LG2, and LG3 are shown in Figure 1. The solutions represent average BCS or dairy form on an average herd-classification visit for a cow that calved at an average age for each

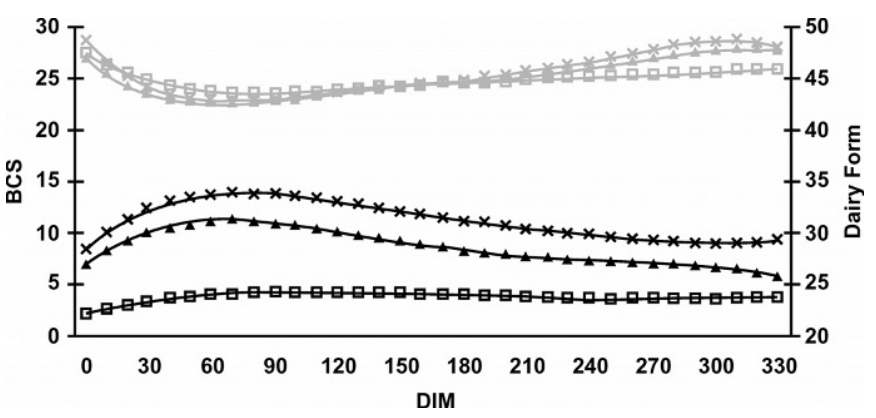

Figure 1. Generalize least squares solutions for BCS (-) and dairy form $(-)$ in lcatation $1(\square)$, lactation $2(\boldsymbol{\Delta})$, and lactations 3 and higher $(\mathbf{x})$.

LG (26.7 in LG1, 40.5 for LG2, and 51.2 for LG3). Nadir BCS was attained at DIM 80, 62, and 68 for LG1, LG2, and LG3, respectively. Dairy form increased in early lactation, and maximum dairy form was attained at DIM 113 in LG1, DIM 70 in LG2, and DIM 73 in LG3.

In general, dairy form is increasing as BCS decreases. Dairy form peaks $33 \mathrm{~d}$ after minimum BCS in first lactation, and the shape of the dairy form curve is different in first lactation than second or third lactation. Dairy form increases with lactation number more than average BCS declines. A different phenotypic relationship between dairy form and stage of lactation in first lactation compared to later lactations may have resulted in a significant interaction between DIM and lactation number with model 3 (MDRR).

The heritability of BCS was estimated to be 0.20 , whereas the repeatability estimate was 0.32 . The heritability and repeatability estimates for dairy form were 0.26 and 0.61 , respectively.

\section{RRA Models}

Heritabilities and correlations were derived from model 2 (RRA) for BCS at 30 mo of age $\left(\mathbf{B C S}_{30}\right), 50$ mo of age $\left(\mathbf{B C S}_{50}\right)$, and change in BCS from $50-30$ mo of age $\left(\mathbf{B C H}_{50-30}\right)$. The heritability estimate changed minimally from $30(0.21)$ to $50 \mathrm{mo}(0.20)$. The genetic correlation between $\mathrm{BCS}_{30}$ and $\mathrm{BCS}_{50}$ was high (0.94), but the phenotypic correlation estimate was only 0.27 .

The heritability estimate for $\mathrm{BCH}_{50-30}$ was 0.03 . When the genetic correlation between BCS at two DIM is high, then genetic variation for change between those two DIM must be low. The phenotypic correlation was not high, indicating that there is appreciable phenotypic variation for change in BCS.

Heritabilities and correlations were derived from the RRA model among dairy form at $30\left(\mathbf{D F}_{\mathbf{3 0}}\right), 50\left(\mathbf{D F}_{\mathbf{5 0}}\right)$ and 50 to 30 mo of age $\left(\mathbf{D C H}_{\mathbf{5 0 - 3 0}}\right)$. The heritability estimate for $\mathrm{DF}_{30}(0.28)$ was similar to that of $\mathrm{DF}_{50}$ 
(0.27). As with BCS, the genetic correlation between $\mathrm{DF}_{30}$ and $\mathrm{DF}_{50}$ was 0.94 , but the phenotypic correlation estimate was higher (0.56) for dairy form. The heritability estimate for $\mathrm{DCH}_{50-30}$ was 0.05 .

Random regression models have been used to describe genetic changes in final score with age at classification (Tsuruta et al., 2002a). Tsuruta et al. (2002a) assumed a constant residual variance across ages and fitted quadratic polynomials for random effects. Random quadratic effects for age at calving would not converge for BCS or dairy form in this study. Averageinformation REML was used here, whereas Tsuruta et al. (2002a) used REMLF90, which uses an expectation maximization-REML algorithm and can be more stable but takes longer to converge (Misztal et al., 2000). Convergence was not attained because of limited variation for a quadratic effect of sire on age and would change our results minimally.

Results from random regression on age at classification for stature, rump angle, thurl width, rear leg set, rear udder width, rear udder height, udder depth, and fore udder attachment were reported by Uribe et al. (2000). In general, traits related to body structure (stature, rump angle, and thurl width) were similar traits genetically across ages, whereas EBV for rear leg set and udder traits tended to change with age. Dairy form is related to body structure and appears to change minimally with age genetically, as does BCS.

\section{MDRR Models}

Multidimensional random regression models (model 3 ) were successfully fit for both BCS and dairy form. The advantage of such a model over a multiple trait random regression model with each LG treated as a separate trait is that the number of parameters to be estimated is greatly reduced (Jensen, 2001). A threetrait model with sire interacted with LP0, LP1, and LP2 and nested within LG would require estimation of 45 (co)variance parameters for the sire effect alone. The current model for BCS required estimation of 10 (co)variance parameters for sire, whereas the model for dairy form required 15 (co)variance parameters be estimated. Separate breeding values for each lactation can still be generated, however.

$\boldsymbol{B C S}$. The estimated heritability curves for BCS in lactations 1, 2, and 3 are shown in Figure 2. Heritability estimates for lactations 1 are from both HEV and HOV models. Heritability estimates for lactation 2 and 3 are from HEV models only.

Heritability estimates peak in midlactation for all lactations. Heritability estimates are highest across first lactation and increase from 0.15 at DIM 0 to 0.24 at DIM 200. The curve of heritability estimates ob-

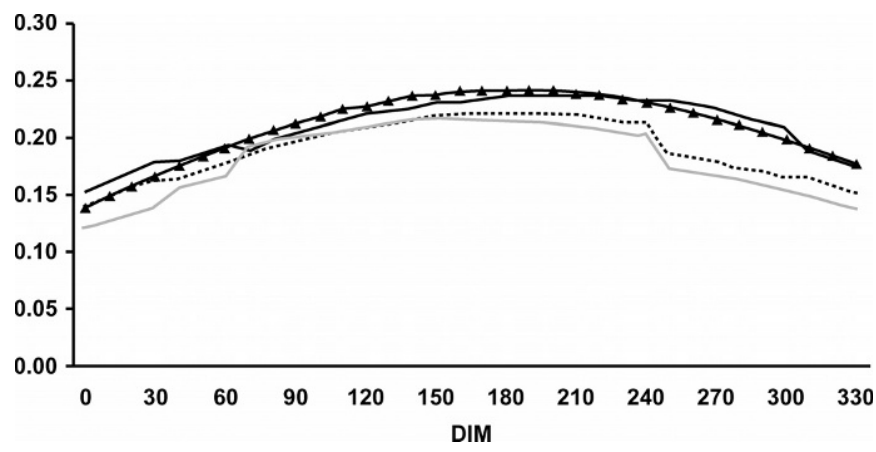

Figure 2. Heritability of BCS in lactation 1 (-), lactation 2 (- - - ), lactation 3 (-) assuming heterogeneous residual variance. Heritability of BCS in lactation 1 (- - -) assuming homogeneous residual variance.

tained from the HOV model is nearly identical to the curve obtained from the HEV model.

Variance component estimates for lactation 1 from HOV and HEV models are shown in Figure 3. The estimate of genetic variance is nearly identical for both models. Residual variance was estimated to be lower in first lactation and during early lactation for the HEV model. This appears to have resulted in a lower PE variance estimate across lactation 1 , especially in early lactation, for the HOV model. Likewise, residual variance is estimated to be somewhat higher in late lactation with the HEV model, corresponding to a higher estimate of PE variance with the HOV model. The end result is a heritability estimate that is nearly identical for both models.

Cubic LP for DIM were used by both Jones et al. (1999) and Veerkamp et al. (2001) to model genetic variation for BCS across the lactation. Attempts to fit cubic LP did not converge in this study. The sire variance reported in this study displays a similar trend to

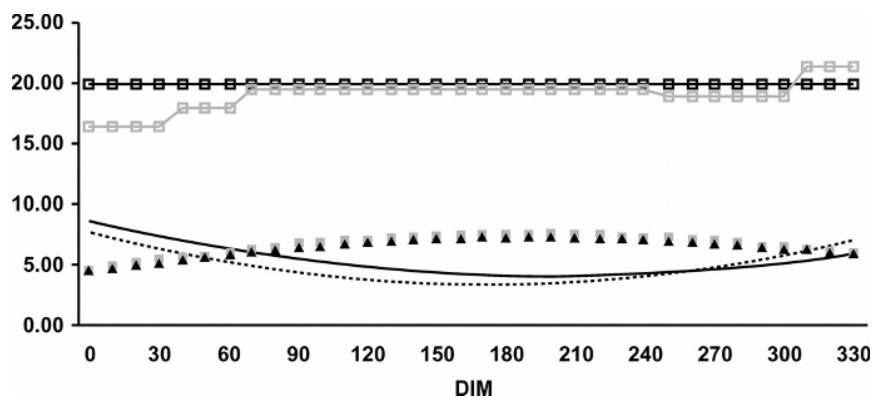

Figure 3. Genetic variation estimate $(\boldsymbol{\Lambda})$, permanent environmental variation estimate (-), and residual variation estimate (- $\square-$, gray scale) for BCS in lactation 1 assuming heterogeneous residual variance. Genetic variation estimate ( $\square$ ), permanent environmental variation estimate $(----)$, and residual variation estimate $(-\square-)$ for BCS in lactation 1 assuming homogeneous residual variance. 
Table 1. Heritabilities (diagonal), genetic (below diagonal), and phenotypic (above diagonal) correlations estimates among BCS at DIM 0, 70 , and 305 in lactations 1, 2, and 3, loss in BCS from d 0 to 70 (0-70), gain in BCS from d 70 to 305 (305-70) and change during the first dry period (Dry, DIM 0 in lactation 2 - DIM 305 in lactation 1).

\begin{tabular}{|c|c|c|c|c|c|c|c|c|c|c|c|c|c|}
\hline \multirow[b]{2}{*}{ Lactation } & \multirow[b]{2}{*}{ DIM } & \multicolumn{3}{|c|}{1} & \multicolumn{3}{|c|}{2} & \multicolumn{3}{|c|}{3} & \multicolumn{2}{|c|}{ BCS Change } & \multirow[b]{2}{*}{ Dry } \\
\hline & & 0 & 70 & 305 & 0 & 70 & 305 & 0 & 70 & 305 & $0-70$ & $305-70$ & \\
\hline 1 & $\begin{array}{r}0 \\
70 \\
305\end{array}$ & $\begin{array}{l}0.15 \\
0.99 \\
0.90\end{array}$ & $\begin{array}{l}0.41 \\
0.19 \\
0.96\end{array}$ & $\begin{array}{l}0.31 \\
0.32 \\
0.19\end{array}$ & $\begin{array}{l}0.34 \\
0.33 \\
0.29\end{array}$ & $\begin{array}{l}0.32 \\
0.31 \\
0.31\end{array}$ & $\begin{array}{l}0.20 \\
0.23 \\
0.32\end{array}$ & $\begin{array}{l}0.21 \\
0.22 \\
0.26\end{array}$ & $\begin{array}{l}0.21 \\
0.23 \\
0.30\end{array}$ & $\begin{array}{l}0.09 \\
0.14 \\
0.29\end{array}$ & $\begin{array}{r}0.02 \\
0.01 \\
-0.02\end{array}$ & $\begin{array}{r}-0.08 \\
-0.05 \\
0.04\end{array}$ & $\begin{array}{r}0.01 \\
-0.01 \\
-0.07\end{array}$ \\
\hline 2 & $\begin{array}{r}0 \\
70 \\
305\end{array}$ & $\begin{array}{l}0.97 \\
0.96 \\
0.85\end{array}$ & $\begin{array}{l}0.96 \\
0.98 \\
0.92\end{array}$ & $\begin{array}{l}0.90 \\
0.96 \\
0.98\end{array}$ & $\begin{array}{l}0.14 \\
0.99 \\
0.90\end{array}$ & $\begin{array}{l}0.31 \\
0.19 \\
0.96\end{array}$ & $\begin{array}{l}0.26 \\
0.29 \\
0.17\end{array}$ & $\begin{array}{l}0.27 \\
0.29 \\
0.30\end{array}$ & $\begin{array}{l}0.29 \\
0.32 \\
0.36\end{array}$ & $\begin{array}{l}0.22 \\
0.27 \\
0.39\end{array}$ & $\begin{array}{r}0.00 \\
-0.01 \\
-0.04\end{array}$ & $\begin{array}{r}-0.02 \\
0.00 \\
0.09\end{array}$ & $\begin{array}{r}0.00 \\
-0.02 \\
-0.07\end{array}$ \\
\hline BCS Change & $\begin{array}{l}0-70 \\
305-70 \\
\text { Dry }\end{array}$ & $\begin{array}{l}-0.60 \\
-0.21 \\
-0.29\end{array}$ & $\begin{array}{l}-0.72 \\
-0.06 \\
-0.43\end{array}$ & $\begin{array}{r}-0.88 \\
0.22 \\
-0.63\end{array}$ & $\begin{array}{l}-0.60 \\
-0.14 \\
-0.23\end{array}$ & $\begin{array}{r}-0.73 \\
0.01 \\
-0.39\end{array}$ & $\begin{array}{r}-0.87 \\
0.30 \\
-0.59\end{array}$ & $\begin{array}{l}-0.57 \\
-0.06 \\
-0.16\end{array}$ & $\begin{array}{r}-0.71 \\
0.08 \\
-0.32\end{array}$ & $\begin{array}{r}-0.84 \\
0.36 \\
-0.52\end{array}$ & $\begin{array}{r}0.01 \\
-0.62 \\
0.89\end{array}$ & $\begin{array}{r}-0.02 \\
0.01 \\
-0.75\end{array}$ & $\begin{array}{r}0.02 \\
-0.05 \\
0.03\end{array}$ \\
\hline
\end{tabular}

the genetic variance estimated from a quadratic LP by Veerkamp et al. (2001). Genetic variance was reported to be highest in midlactation and lower at the beginning and end of lactation. The estimate of genetic variance increased near the end of lactation when cubic LP were fit, but the cubic term explained only $0.016 \%$ of the genetic variation (Veerkamp et al., 2001).

Heritabilities, genetic, and phenotypic correlation estimates among BCS at DIM 0, 70, and 305 in first, second, and third lactation are given in Table 1. Additionally, heritability and correlation estimates among BCS and change in BCS from DIM 0 to $70\left(\mathbf{B C H}_{\mathbf{0}}\right.$ 70), 305 to $70\left(\mathbf{B C H}_{305-70}\right)$, and change from DIM 0 in lactation 2 - DIM 305 in lactation $1\left(\mathbf{B C H}_{\mathbf{D P}}\right)$ are also given in Table 1. Correlations among the above traits and DIM $305-178\left(\mathbf{B C H}_{\mathbf{3 0 5}-178}\right)$ and DIM $178-70$ $\left(\mathbf{B C H}_{178-70}\right)$ were calculated but not shown.

These points were chosen to represent BCS at calving (DIM 0), nadir BCS (DIM 70), and BCS at the end of lactation (DIM 305). A high PTA for $\mathrm{BCH}_{0-70}$ indicates that daughters of that sire lose more body condition than average from DIM 0 to 70, whereas a high PTA for $\mathrm{BCH}_{305-70}$ indicates that daughters of that sire gain more body condition than average from DIM 70 to 305 . A high value for $\mathrm{BCH}_{\mathrm{DP}}$ indicates that daughters of that sire gain more body condition during the dry period than average.

Genetic correlation estimates among BCS at DIM 0, 70 , and 305 in lactation 1 through 3 range from 0.77 (between DIM 0 in lactation 1 and DIM 305 in lactation 3 ) to 0.99 . Genetic correlation estimates within a lactation are 0.90 and above, whereas genetic correlation estimates at the same DIM in different lactations are 0.88 and above. Several authors have found high genetic correlations between BCS at different DIM and in different lactations using both random regression models and multiple-trait models where BCS from different stages of lactation were considered different traits (Jones et al., 1999; Dechow et al., 2001; Gallo et al., 2001; Koenen et al., 2001).

Phenotypic correlation estimates are lower than the genetic correlation estimates, ranging from 0.09 to 0.41 . It may be possible that PE covariances, and thus phenotypic correlations, were underestimated. Few cows would have BCS observations at or near two particular DIM and only LP1 could be fit for PE effects. Thus, the $\mathrm{PE}$ estimate for a particular cow on a given DIM is based on a straight line with only one to three observations available to estimate that line. If $\mathrm{PE}$ covariance is underestimated, the estimated residual variance for change in BCS would be overestimated, and heritability underestimated. The heritability of $\mathrm{BCH}_{0-70}$ and $\mathrm{BCH}_{305-70}$ were estimated to be 0.01 , whereas the heritability estimate of $\mathrm{BCH}_{\mathrm{DP}}$ was 0.03 . Other estimates of the heritability of BCS loss in the first 2 to $3 \mathrm{mo}$ of lactation range from 0.01 to 0.09 (Pryce et al., 2001; Berry et al., 2002; Dechow et al., 2002). Whereas the heritability of BCS change could be underestimated here, it seems clear that the genetic correlation among BCS at different stages of lactation and across lactations are high, and that the heritability of BCS change is much less than the heritability of the level of BCS.

The heritability estimates of BCS change are low and genetic correlations among levels of BCS and BCS change should be interpreted with caution. Correlations among levels of BCS and BCS change do appear to be consistent with other reports, however. Genetic correlation estimates between $\mathrm{BCH}_{0-70}$ and the level of BCS range from -0.60 to -0.87 (Table 1 ). Genetic correlations are stronger (negative) between $\mathrm{BCH}_{0-70}$ and the level of BCS at DIM 70 and 305 than at DIM 0. Dechow et al. (2002) reported that BCS loss during the first third 
of lactation was genetically correlated more strongly with postpartum BCS (range -0.56 to -0.99 ) than with BCS at calving (range -0.11 to -0.48 ). It appears that cows genetically inclined to have higher BCS at calving lose less body condition during the first months of lactation and have higher BCS later in lactation.

Early lactation cows are in negative energy balance and must mobilize body condition to support early lactation production (Bauman and Currie, 1980). There is variation on the severity and duration of negative energy balance. Cows genetically inclined to have higher levels of BCS appear to lose less BCS, and thus have less severe negative energy balance, in early lactation. Additionally, selection that increases negative energy balance in early lactation would do so by lowering BCS during the lactation more than BCS at calving.

The genetic correlation between $\mathrm{BCH}_{0-70}$ and $\mathrm{BCH}_{305-70}$ was -0.62 . Cows genetically inclined to lose more body condition than average from DIM 0 to 70 appear to gain less BCS from DIM 70 to 305 . However, the genetic correlation between $\mathrm{BCH}_{0-70}$ and $\mathrm{BCS}$ change from $\mathrm{BCH}_{305-178}$ is 0 and the genetic correlation estimate between $\mathrm{BCH}_{0-70}$ and $\mathrm{BCH}_{178-70}$ is -0.95 (not shown). Body condition score gain from any DIM after 178 to 305 is positively correlated with $\mathrm{BCH}_{0-70}$. Genetic correlation estimates between $\mathrm{BCH}_{\mathrm{DP}}$ and $\mathrm{BCS}$ at DIM 0,70 , and 305 were negative, ranging from -0.16 to -0.63 , whereas the genetic correlation estimate between $\mathrm{BCH}_{\mathrm{DP}}$ and $\mathrm{BCH}_{0-70}$ was 0.89 .

This appears to agree with observations of Berry et al. (2002). They reported a genetic correlation between BCS at DIM 5 to 60 and BCS at DIM 180 to 120 of -0.26 (the authors used DIM 60 to 5 so the signs have been reversed here). The genetic correlation between BCS at DIM 5 to 60 and DIM 240 to 180 was reported to be 0.37 .

Cows genetically inclined to have a high level of BCS at calving (DIM 0) appear inclined to lose less body condition from DIM 0 to 70, and gain less BCS during the dry period. Cows genetically inclined to lose more BCS from DIM 0 to 70 appear to gain less body condition through midlactation and then gain more body condition than average in late lactation and the dry period.

The relationship between the level of BCS and changes in BCS may be due, in part, to their relationship with milk production. While slightly positive genetic correlation estimates between BCS at calving and production have been reported, genetic correlation estimates for BCS during the lactation and milk, fat, or protein production are moderately negative (Dechow et al., 2001; Gallo et al., 2001; Veerkamp et al., 2001; Berry et al., 2002). Genetic correlation estimates between BCS loss in early lactation and total lactation

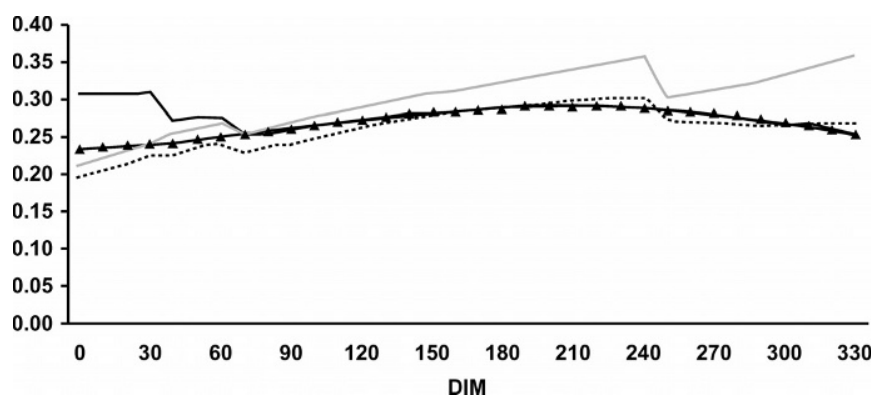

Figure 4. Heritability of dairy form in lactation 1 (-), 2 (--- ), lactation 3 ( - ) assuming heterogeneous residual variance. Heritability of dairy form in lactation $1\left(-\mathbf{\Lambda}_{-}\right)$assuming homogeneous residual variance.

milk production range from 0.09 to 0.50 (Pryce et al., 2001; Dechow et al., 2002).

Genetic correlation estimates between BCS and production are not constant across the lactation, however. When BCS at different stages of lactation are treated as separate traits, genetic correlation estimates between production and BCS were reported range from 0.22 to -0.27 at or near calving, -0.06 to -0.43 in midlactation, and from 0.07 to -0.31 in late lactation (Dechow et al., 2001). Veerkamp et al. (2001) reported that genetic correlations between BCS and production became stronger (negative) as the lactation progressed using random regression models.

Cows genetically inclined to produce higher levels of milk tend to have lower levels of BCS, lose more BCS in early lactation, and have more severe negative energy balance in early lactation. Higher-producing cows likely partition more nutrients toward production and less toward replenishing body condition during mid- to late lactation, and then recover body condition at a more rapid rate in late lactation and the dry period.

Dairy form. The estimated heritability curve of dairy form across lactations one, two, and three is given in Figure 4. From the HEV model, heritability estimates for lactation 1 are highest at the beginning of lactation (0.31), but early lactation heritability estimates are lowest for lactation 2 and 3. The heritability estimate for first lactation is lowest at the beginning of the lactation if homogeneous residual variance is assumed. The heritability estimate for second lactation peaks at DIM $240(0.30)$. In lactation 3, heritability increased across the lactation and was highest (0.36) at DIM 240 and 335.

The estimated variance components for lactation 1 from HEV and HOV models are given in Figure 5. Genetic variance estimates from both models are nearly identical. As with BCS, residual variance in first lactation was lower than average residual variance in second 


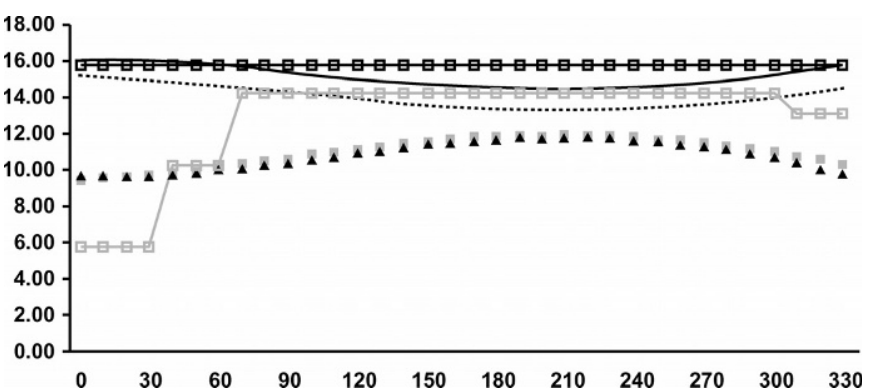

Figure 5. Genetic variation estimate $(\boldsymbol{\Lambda})$, permanent environmental variation estimate (-), and residual variation estimate $(-\square-$, gray scale) for dairy form in lactation 1 assuming heterogeneous residual variance. Genetic variation estimate $(\mathbf{\square})$, permanent environmental variation estimate (- - - ), and residual variation estimate (- $\square-$ ) for BCS in lactation 1 assuming homogeneous residual variance.

and third lactations, resulting in a lower $\mathrm{PE}$ variance when residual variance was held constant. Because models that included PE interacted with LP did not converge, $\mathrm{PE}$ variance estimates did not compensate for lower early lactation residual variance, resulting in lower heritability estimates for dairy form with the HOV model at DIM 0 for lactations 1 (7\% lower), 2 (3\% lower), and 3 (4\% lower).

Residual variance was particularly low in the first month of lactation 1, resulting in a high heritability estimate in the first month of lactation 1 with the HEV model. This is likely an effect of type appraisal procedures for early first lactation cows. Classifiers have the option of not classifying early-lactation cows if they feel that a cow has not had time to recover from the stress of calving and is not in proper condition. Cows that are scored in that first month are therefore a select group. Early first-lactation cows that are in condition to be classified and that producers would like to have scored are likely to be above average for type, which could bias variance estimates in early lactation. The average final score of first-lactation cows evaluated during the first month of lactation was 79.4 in this dataset, whereas the average final score of cows evaluated after the first month of first lactation was 76.5.

Many random regression models have displayed a rapid increase in heritability estimates at the ends of the measured time scale, which is usually DIM (Misztal et al., 2000). This increase is likely an artifact of the random regression model. Stages of lactation where observations are abundant may be modeled well, whereas the beginning and end of lactations, which typically contain fewer observations, are modeled poorly (Misztal et al., 2000). The increasing heritability estimate across third lactation is likely an artifact of the model used here. Lactation 3 in late lactation is near the end of the observation for two time scales (lactation number and DIM), and there were only 266 observations in mo 11 for lactations 3 and higher.

Genetic correlation estimates among dairy form scores at DIM 0, 70, and 305 and in lactations 1 through 3 (not shown) ranged from 0.60 to 0.98 . The heritability estimates of change in dairy form scores in lactation 1 from DIM 0 to $70\left(\mathbf{D C H}_{\mathbf{0 - 7 0}}\right)$ was 0.05 , as was the heritability estimate for change in dairy form from DIM 305 to 70 .

Because an interaction between DIM and lactation effects was fitted, change in dairy form in one lactation was not necessarily the same in other lactations. The genetic correlation estimate for $\mathrm{DCH}_{0-70}$ among lactations 1,2 , and 3 ranged from 0.43 (between lactations 1 and 3) to 0.88 (between lactations 2 and 3).

The genetic correlation estimates between the level of dairy form and $\mathrm{DCH}_{0-70}$ in the corresponding lactation was 0.08 at DIM 0 in lactation 1 and negative elsewhere (range -0.23 to -0.90 ). A negative value for $\mathrm{DCH}_{0-70}$ represents an increase in dairy form from DIM 0 to 70. It appears that cows with a high level of dairy form tended to increase in dairy form in early lactation, especially later lactations. Genetic correlation estimates tended to be strongest between $\mathrm{DCH}_{0-70}$ and DIM 305 (range -0.55 to -0.90 ).

\section{MT and MDRR Models}

Genetic parameter estimates obtained from MDRR (model 3) for lactations 1, 2, and 3 were similar to those obtained from MT (model 4). Genetic correlation estimates obtained from MT models among BCS in LG 1, LG 2, and LG 3 ranged from 0.94 to 0.98 , whereas genetic correlation estimates obtained from MDRR models among first, second, and third lactations ranged from 0.92 to 0.98 . Standard errors of the genetic correlations for the MT model ranged from 0.02 to 0.03 . The heritability estimates from the MT model ranged from 0.20 (lactation 2 and 3 ) to 0.22 (lactation 1), whereas heritability estimates for the MDRR model ranged from 0.18 (lactation 3) to 0.21 (lactation 1).

Genetic correlation estimates ranged from 0.96 to 1.01 among LG 1, LG 2, and LG3 for dairy form for the MT model. Standard errors for the genetic correlations ranged from 0.01 to 0.02 . The 2 -trait model with dairy form in LG2 and LG3 failed to remain positive definite. If the genetic correlation between two traits is near 1 , a genetic correlation greater than 1 may be within the sampling error. Rather than bending covariance matrices to remain positive definite, the covariance estimate is left as sampled by ASREML.

Genetic correlation estimates ranged from 0.92 to 0.98 for lactations 1,2 , and 3 from the MDRR model. 
Table 2. Genetic correlation $\left(r_{g}\right)$ estimates and phenotypic correlation $\left(\mathrm{r}_{\mathrm{p}}\right)$ estimates BCS and dairy form in the following months of lactation: 1 through 2 (P1), 3 through 4 (P2), 5 through 6 (P3), 7 through 8 (P4) and 9 through $11(\mathrm{P} 5)^{1}$

\begin{tabular}{lll}
\hline $\begin{array}{l}\text { Lactation } \\
\text { stage }\end{array}$ & $\mathrm{r}_{\mathrm{g}}$ & $\mathrm{r}_{\mathrm{p}}$ \\
\hline P1 & -0.63 & -0.38 \\
P2 & -0.67 & -0.42 \\
P3 & -0.72 & -0.45 \\
P4 & -0.69 & -0.46 \\
P5 & -0.61 & -0.45 \\
\hline
\end{tabular}

${ }^{1}$ Standard errors for the genetic correlations ranged from 0.04 to 0.08 and standard errors for the phenotypic correlations were 0.01 .

Heritability estimates ranged from 0.24 (lactation 2 ) to 0.28 (lactation 1) with the MT model, whereas they ranged from 0.26 (lactation 2) to 0.28 (lactation 3) with the MDRR model.

\section{BCS and Dairy Form}

Correlation estimates among BCS and dairy form in different lactation periods are given in Table 2. Phenotypic correlations are moderate, ranging from -0.38 to -0.46 . It is possible to have an open ribbed cow that has a high level of BCS, or a tight ribbed cow with low BCS at the phenotypic level.

Genetic correlation estimates are stronger (range -0.61 to -0.72 ) than the phenotypic correlation estimates. Bulls that sire daughters high in dairy form also tend to sire daughters that have lower BCS than average. Genetic parameters for BCS and dairy form change in a similar manner across the lactation as well. Genetic variance estimates (Figures 2 and 4 ) tend to be lowest in early lactation, highest in the middle of lactation, and decline toward late lactation. The genetic correlation estimates between BCS and dairy form tend to be strongest when the genetic variances for both traits are the highest.

Whereas BCS and dairy form are not the same traits phenotypically, both contribute to angularity and have a moderate to strong genetic relationship. A cow with high angularity is open ribbed (or has a high dairy form), is free of excess fleshing, and has a flat, clean bone structure (Interbull, 2003b). The genetic correlation between dairy form in the United States and angularity in the United Kingdom is 0.89 (Interbull, 2003a). Correlations between BCS and angularity were reported to range from -0.47 to -0.77 in a research herd from the United Kingdom (Veerkamp and Brotherstone, 1997).

Bone quality is measured on Canadian Holsteins and contributes positively to dairy character scores (Holstein Canada, 2003). The genetic correlation between dairy character in Canada and dairy form in the US is reported to be 0.86 (Interbull, 2003a). A genetic correlation estimate between BCS and bone quality was reported to be -0.44 in a pilot study in Canada (van Dorp and Boettcher, 1999). Cows with low BCS likely have less tissue surrounding the cannon bone, thus appearing to have a more refined or "flatter" bone structure in their rear legs.

Bulls that sire daughters high in dairy form tend to have daughters that are open ribbed, low in BCS, and flat boned, thus appearing to be more angular. There are some differences between BCS and dairy form genetically. Body condition score was reported to be strongly correlated with strength (0.69), whereas dairy form was not (-0.11) (Dechow et al., 2003). Despite the negative genetic correlation between them, both BCS and dairy form were reported to be positively correlated with stature and frame in the same study (range 0.20 to 0.27 ).

The increase in dairy form with lactation number (Figure 1) could be due to an increase in size as cows mature. As a cow grows and become longer, space between ribs may increase, resulting in a higher dairy form. Growth in stature and frame during first lactation could also be responsible for the general increase in dairy form across first lactation that was not observed across other lactations. Increased size with maturity does not appear to have a large impact on BCS, however.

\section{Predicted Transmitting Abilities}

Correlations among PTA for BCS and dairy form in different lactations and from various models are given in Table 3. Correlations among PTA from all models were high, indicating that all models performed consistently. Correlations among PTA from the RPT model and all other models were 0.983 and higher for BCS, and 0.95 and higher for dairy form.

In first and second lactation, PTA from MT models are more highly correlated with PTA generated with MDRR models for the corresponding lactation than with PTA generated with RPT models. This may indicate that MDRR PTA are slightly more accurate for lactations 1 and 2 than the RPT models. That was not true for third lactation, and MDRR models may not have fit third lactation as well as lactations 1 and 2 .

Predicted transmitting abilities at $30 \mathrm{mo}$ of age from RRA models were more highly correlated with PTA for first lactation from MT and MDRR models than second or third lactations. Predicted transmitting abilities at 50 mo of age from RRA models were most highly correlated with second lactation PTA from MT and MDRR models. It would be expected that PTA for younger ages (30 mo) be closer to PTA from first lactation, whereas 
Table 3. Correlations among sire PTA from repeatability (RPT) models, PTA from lactations 1 (MT1), 2 (MT2) and 3 and higher (MT3) from multiple trait models, lactation 1 (RR1), lactation 2 (RR2), and lactation 3 (RR3) from random regression models on DIM and lactation number, and 30 (RR30), and 50 mo (RR50) from random regression models on age at classification for BCS (below diagonal) and dairy form (above diagonal).

\begin{tabular}{llllllllll}
\hline & RPT & MT1 & MT2 & MT3 & RR1 & RR2 & RR3 & RR30 & RR50 \\
\hline RPT & & 0.978 & 0.979 & 0.950 & 0.996 & 0.997 & 0.986 & 0.994 & 0.994 \\
MT1 & 0.984 & & 0.994 & 0.947 & 0.984 & 0.975 & 0.955 & 0.984 & 0.969 \\
MT2 & 0.983 & 0.988 & & 0.944 & 0.979 & 0.981 & 0.970 & 0.977 & 0.978 \\
MT3 & 0.988 & 0.987 & 0.998 & & 0.948 & 0.950 & 0.940 & 0.950 & 0.946 \\
RR1 & 0.997 & 0.989 & 0.979 & 0.976 & & 0.993 & 0.975 & 0.998 & 0.987 \\
RR2 & 0.998 & 0.980 & 0.985 & 0.984 & 0.995 & & 0.994 & 0.989 & 0.998 \\
RR3 & 0.988 & 0.963 & 0.982 & 0.982 & 0.980 & 0.995 & & 0.968 & 0.995 \\
RR30 & 0.995 & 0.987 & 0.975 & 0.973 & 0.997 & 0.991 & 0.974 & & 0.983 \\
RR50 & 0.994 & 0.975 & 0.986 & 0.984 & 0.989 & 0.997 & 0.996 & 0.983 & \\
\hline
\end{tabular}

PTA for older ages (50 mo) would be closer to PTA from lactations 2 and 3 if the RRA model fit well.

Predicted transmitting abilities between DIM 0, 70, and 305 in lactations 1, 2, and 3 from MDRR models were also generated and correlated with PTA from RPT models (not shown). Correlations ranged from 0.977 to 0.997 for BCS and from 0.948 to 0.996 for dairy form. The RPT models also appear to be accurate for any DIM for both BCS and dairy form.

\section{CONCLUSIONS}

Previously reported relationships among BCS, dairy form, reproductive performance, and cow health indicate that selection for higher BCS or lower dairy form may improve reproductive performance and cow health. National genetic evaluations for BCS are not currently available, but could be generated. Body condition score has a strong genetic correlation with dairy form and BCS evaluations would only be necessary if selection for BCS is shown to improve cow health or reproductive performance beyond what is possible with selection for dairy form.

Selection in the United States has been for cows with higher dairy form, and thus lower BCS, because dairy form is favorably correlated with yield. When analyzing the merit of cows in the absence of production records, at cattle shows or during linear classification for example, some preference to those cows with higher dairy form may be justified. However, reported correlations between dairy form and production are moderate and preference for thin cows that otherwise appear equal in production to other cows should be discouraged. Preference for higher dairy form as an indicator of production is not necessary when reliable production records are available and genetic selection should be for those bulls that sire daughters high in production but low in dairy form.

Random regression models for BCS or dairy form could be used to generate PTA for an age or DIM when heritability was highest, or be used to generate PTA for change in BCS or dairy form. Evaluations from random regression models may be of value if a strong association were found between change in BCS or dairy form and an economically important trait, such as reproductive performance. If correlations of BCS or dairy form with an important trait changed across the lactation, then evaluations from random regression models for DIM when the relationship is strongest might be of value. However, genetic correlations between BCS or dairy form at different DIM, lactations, and ages are high and change in BCS and dairy form is not as heritable as the level of BCS or dairy form. Large daughter groups would be necessary to estimate accurate evaluations for change in BCS or dairy form.

The repeatability models used currently in national genetic evaluation programs in the United States would appear to generate accurate PTA for BCS or dairy form at any age or stage of lactation.

\section{ACKNOWLEDGMENTS}

Appreciation is expressed to the Holstein Association USA, Inc. for providing data and financial assistance, and to the National Milk Producers Federation for providing financial assistance.

\section{REFERENCES}

Bauman, D. E., and W. B. Currie. 1980. Partitioning of nutrients during pregnancy and lactation: A review of mechanisms involving homeostasis and homeorhesis. J. Dairy Sci. 63:1514-1529.

Berry, D. P., F. Buckley, P. Dillon, R. D. Evans, M. Rath, and R. F. Veerkamp. 2002. Genetic parameters for level and change of body condition score and body weight in dairy cows. J. Dairy Sci. 85:2030-2039.

Dechow, C. D., G. W. Rogers, and J. S. Clay. 2001. Heritabilities and correlations among body condition scores, production traits, and reproductive performance. J. Dairy Sci. 84:266-275.

Dechow, C. D., G. W. Rogers, and J. S. Clay. 2002. Heritability and correlations among body condition score loss, body condition score, production, and reproductive performance. J. Dairy Sci. 85:3062-3070. 
Dechow, C. D., G. W. Rogers, L. Klei, and T. J. Lawlor. 2003. Heritabilities and correlations among body condition score, dairy form, and selected linear type traits. J. Dairy Sci. 86:2236-2242.

Gallo, L., P. Carnier, M. Cassandro, R. Dal Zotto, and G. Bittante. 2001. Test-day genetic analysis of condition score and heart girth in Holstein Friesian cows. J. Dairy Sci. 84:2321-2326.

Gilmour, A. R., B. R. Cullis, S. J. Welham, and R. Thompson. 2002. ASREML Reference Manual. ftp:ftp.res.bbsrc.ac.uk/pub/aar.

Hansen, M., M. S. Lund, M. K. Sorensen, and L. G. Christensen. 2002. Genetic parameters of dairy character, protein yield, clinical mastitis, and other diseases in the Danish Holstein cattle. J. Dairy Sci. 85:445-452.

Holstein Canada. 2003. Dairy character. http://www.holstein.ca/English/TC/dairychar.asp Accessed Jan. 7, 2003.

Interbull. 2003a. Estimated genetic parameters: Appendix II. http:// www-interbull.slu.se/conform/framesida-conf.htm. Accessed Jan. 7, 2003.

Interbull. 2003b. Service documentation Holstein conformation. http: //www-interbull.slu.se/service_documentation/Conformation/ framesida-conformation.htm. Accessed Jan. 7, 2003.

Jensen, J. 2001. Genetic evaluation of dairy cattle using test-day models. J. Dairy Sci. 84:2803-2812.

Jones, H. E., I. M. S. White, and S. Brotherstone. 1999. Genetic evaluation of Holstein Friesian sires for daughter condition-score changes using a random regression model. Anim. Sci. 68:467-475.

Koenen, E. P. C., R. F. Veerkamp, P. Dobbelaar, and G. De Jong. 2001. Genetic analysis of body condition score of lactating Dutch Holstein and Red-and-White heifers. J. Dairy Sci. 84:1265-1270.

Kirkpatrick, M., D. Lofsvold, and M. Bulmer. 1990. Analysis of the inheritance, selection and evolution of growth trajectories. Genetics 124:979-993.

Misztal, I., T. Strabel, J. Jamrozik, E. A. Mantysaari, and T. H. Meuwissen. 2000. Strategies for estimating the parameters needed for different test-day models. J. Dairy Sci. 83:1125-1134.
Pryce, J. E., M. P. Coffey, and G. Simm. 2001. The relationship between body condition score and reproductive performance. J. Dairy Sci. 84:1508-1515.

Rogers, G. W., G. Banos, and U. Sander-Nielsen. 1999. Genetic correlations among protein yield, productive life, and type traits from the United States and diseases other than mastitis from Denmark and Sweden. J. Dairy Sci. 82:1331-1338.

Short, T. H., and T. J. Lawlor. 1992. Genetic parameters of conformation traits, milk yield, and herd life in Holsteins. J. Dairy Sci. 75:1987-1998.

Tsuruta, S., I. Misztal, L. Klei, and T. J. Lawlor. 2002a. Analysis of age-specific predicted transmitting abilities for final scores in Holsteins with a random regression model. J. Dairy Sci. 85:1324-1330.

Tsuruta, S., I. Misztal, T. J. Lawlor, and L. Klei. 2002b. Estimation of changes of genetic parameters over time for type traits in Holsteins using random regression models. Proc. 7th World Congr. Genet. Appl. Livest. Prod., Montpellier, France.

Uribe, H., L. R. Schaeffer, J. Jamrozik, and T. J. Lawlor. 2000. Genetic evaluation of dairy cattle for conformation traits using random regression models. J. Anim. Breed. Genet. 117:247-259.

van Dorp, R., and P. Boettcher. 1999. Technical report: Genetic parameters of mobility, body condition score, and conformation traits. http://cgil.uoguelph.ca/pub/pbpapers/gebtc99-4.htm. Accessed Jan. 7, 2003.

Veerkamp, R. F., and S. Brotherstone. 1997. Genetic correlations between linear type traits, food intake, liveweight and condition score in Holstein-Friesian dairy cattle. Anim. Sci. 64:385-392.

Veerkamp, R. F., E. P. C. Koenen, and G. De Jong. 2001. Genetic correlations among body condition score, yield, and fertility in first-parity cows estimated by random regression models. J. Dairy Sci. 84:2327-2335. 